\title{
ARTÍCULOS
}

\section{SACANDO LOS COLORES AL PAISAJE: LA CROMOTOPONIMIA DE LAS ISLAS BALEARES}

\author{
BRINGING OUT THE COLOUR IN THE LANDSCAPE: THE CHROMOTOPONYMY OF \\ THE BALEARIC ISLANDS
}

\section{Antoni Ordinas Garau ${ }^{1}$}

Jaume Binimelis Sebastián²

Universitat de les Illes Balears

Recibido: 3 de septiembre de 2018; Aprobado: 22 de febrero de 2019

\begin{abstract}
Cómo citar este artículo / Citation: Ordinas Garau, Antoni y Jaume Binimelis Sebastián. 2020. "Sacando los colores al paisaje: la cromotoponimia de las islas Baleares». Disparidades. Revista de Antropología 75(1): e012. doi: <https://doi.org/10.3989/ dra.2020.012>.
\end{abstract}

RESUMEN: La toponimia describe el paisaje, actual e histórico, a través de la percepción de sus habitantes. Mediante los principios de transparencia y significatividad territorial, los nombres de lugar reflejan las características geográficas, entre las que destaca el color como un rasgo muy visible y llamativo del terreno. El análisis de la cromotoponimia permite obtener una visión cromática del paisaje balear con resultados significativos a partir de la aplicación de la teoría de Berlin y Kay sobre el orden de las etapas evolutivas de las culturas en relación a los términos básicos del color.

PALABRAS CLAVE: Toponimia; Cromotoponimia; Paisaje; Islas Baleares.

ABSTRACT: Toponymy describes the contemporary and historical landscape through the perception of its inhabitants. Using principles of transparency and territorial significativity, place names reflect geographical characteristics, in which colour stands out as a visible and striking feature of the land. The analysis of the chromotoponymy of the Balearic archipelago provides a chromatic vision of the landscape, with significant results obtained by applying Berlin and Kay's theory on the order of a culture's evolutionary stage in relation to basic colour terms.

KEYWORDS: Toponymy; Chromotoponymy; Landscape; Balearic Islands.

Copyright: (C) 2020 CSIC. Este es un artículo de acceso abierto distribuido bajo los términos de la licencia de uso y distribución Creative Commons Reconocimiento 4.0 Internacional (CC BY 4.0).

1 Correo electrónico: antoni.ordinas@uib.es. ORCID iD: <https://orcid.org/0000-0002-7210-0276>.

2 Correo electrónico: jaume.binimelis@uib.es. ORCID iD: <https://orcid.org/0000-0002-5256-0371>. 


\section{LA CARACTERIZACIÓN DEL PAISAJE A TRAVÉS DE LA TOPONIMIA}

Para comprender un paisaje construido es necesario entender sus representaciones escritas y orales (Nogué y Albet 2004) y en este sentido no hay duda de que la toponimia puede identificar y reflejar aspectos de la cultura, el patrimonio ${ }^{3}$ y el paisaje, convirtiéndose en un indicador privilegiado para la interpretación del territorio. El propio mecanismo de fijación de los topónimos ya explica su relevancia como indicadores de paisaje. Su función descriptiva se fundamenta en que cada uno contiene información sobre la estrecha relación entre el hombre y el lugar desde el momento en el que ha sido identificado mediante la asignación de un nombre propio. A partir del simple hecho de asignarle un nombre, la toponimia transmite las propiedades del territorio que identifica. Nombrar los espacios, según Claval (1995), es impregnarlos de cultura y poder. Más aún, la información que se deriva del análisis toponímico revela datos geográficos, hechos y acontecimientos históricos y sociales de una región en su dimensión espaciotemporal (Dorion 1986). De ahí que la densidad toponímica sea indicadora del grado de información a obtener sobre la interacción del hombre con el territorio, de la intensidad de su aprehensión cultural.

El análisis de la toponimia evidencia cómo una importante proporción de topónimos presentan un carácter eminentemente descriptivo (Tort 2000), corroborando tanto la equivalencia entre las denominaciones de nombres de lugar y nombres geográficos como la identificación entre geografía y descripción de la tierra. A partir de ambas proposiciones se forma el silogismo por el que se infiere la estrecha relación entre la toponimia y la descripción que convierte en relevante la utilidad de la toponimia como fuente de información y descripción del territorio. Si resulta obvio considerar la descripción como un método adecuado en la formación del conocimiento geográfico, no lo es menos el potencial toponímico por su importante contribución en la descripción de los emplazamientos que además localizan e identifican. Sin embargo, no todos los topónimos presentan el mismo grado de transparencia en la obtención

3 La toponimia también forma parte de lo que actualmente se ha rebautizado como patrimonio inmaterial o intangible, concepto, por otra parte, críticamente cuestionado (Santamarina 2013) ante su auge y su carácter contradictorio y paradójico. de información, pues los hay ininteligibles al pertenecer a antiguos substratos lingüísticos, mostrando una mayor opacidad y resistencia a transmitirla. Su estudio a partir de diccionarios etimológicos y obras especializadas permite en muchos casos superar estos obstáculos y desencriptar la información oculta tras sus nombres.

\subsection{TOPONIMIA Y PERCEPCIÓN}

La Antropología, la Sociología y la Psicología pueden ser de gran ayuda para explicar los mecanismos que rigen en la aparición de la toponimia desde la percepción socioespacial como campo de estudio de la Psicología social (Rose-Redwood, Alderman y Azaryahu 2010). La información proporcionada por un topónimo se puede analizar a partir de su significado, transparente u opaco (Radding y Western 2010), o de su propia realidad, pasando por la obtenida al relacionar ambas, a veces no coincidentes, por lo que nos informan sobre apreciaciones subjetivas. La percepción personal y mediatizada de la realidad se acopla perfectamente al hecho toponímico como resultado de la percepción, ya sea originalmente individual o colectiva, expresada a través del nombre que se liga a un lugar. Por tanto, a la percepción intrínseca de la toponimia debemos sumar la percepción de sus usuarios que afecta múltiples aspectos, no solo geográficos y económicos, sino también culturales, sociológicos y lingüísticos que en ella se reflejan. En este sentido, Nash (2015) propone el concepto de etnografía toponímica donde se aúnan los contextos culturales y ecológicos en el estudio de la toponimia, especialmente de las islas, y destaca su relación con la caracterización del paisaje.

Los topónimos, fruto de culturas diversas, constituyen un conocimiento selectivo susceptible de configurar un mapa mental, de elaboración y carácter local, que refleja la percepción de los habitantes sobre su entorno. La función localizadora de la toponimia implica una serie de percepciones, con mayor riqueza y precisión en los lugares o escenarios donde la vida transcurre con mayor densidad. Así, los nombres de lugar, claves en el proceso de comunicación, denotan las características territoriales percibidas por la población local. El número y la densidad de los topónimos ahonda en la información sobre el nivel de humanización y aprehensión cultural del territorio. Hunn (1994) ha estudiado detenidamente en diversos grupos aborígenes la correlación positiva entre den- 
sidad toponímica y densidad de población, observando la lista de nombres de lugar que sus informantes sienten como propia, es decir, de topónimos activamente recordados y reconocidos. Dicha cuantificación de la percepción conlleva que, en regiones densamente pobladas, también la toponimia menor o microtoponimia obtiene mayor densidad, aunque el radio de conocimiento territorial, y toponímico, de cada informante es menor, en correlación directa con el espacio vivido, pues el repertorio toponímico de cada habitante depende de su experiencia vital. La de algunos se desarrolla en un territorio más vasto, por lo que su repertorio también cubre mayor extensión, aunque con menor densidad y en el que abunda la macrotoponimia o toponimia mayor que jalona sus rutas cotidianas. Contrasta con la de otros de mayor densidad y calidad toponímica, al circunscribirse a espacios más reducidos de intensas y prolongadas vivencias. Este fenómeno explica asimismo las abundantes repeticiones toponímicas $u$ homonimias que se producen en territorios relativamente cercanos, pero no lo suficiente como para provocar interferencias en la comunicación entre usuarios que comparten el mismo espacio vivido y sus correspondientes topónimos. Como señala Riesco (2010), la homonimia es un fenómeno tan omnipresente en la toponimia menor que casi todos los nombres de lugar tienen dobletes en cada comarca, con las variantes previsibles dentro de la dispersión evolutiva de la lengua.

Frente a todo ello, resulta cada vez más frecuente en nuestros días la toponegligencia o tendencia a perder el sentido del lugar que tiene su origen en la crisis de desarraigo presente. Los transportes rápidos nos hacen perder la noción precisa del paisaje y sus contenidos complejos, pues se hace difícil conocer la realidad rural desde la ventanilla y la velocidad de un vehículo. También supone la incomunicación con los paisanos del lugar, buenos informadores del territorio, con los que antes se facilitaba la consulta pausada mediante un recorrido a pie o en carruaje. Todo ello reduce el conocimiento y lleva a la pérdida de los topónimos (Afonso 1988). Los cambios socioeconómicos han empobrecido la diversidad hasta llevarnos a la uniformidad de un espacio abstracto e impersonal, el no-lugar. De hecho, la incapacidad de actuar sobre el paisaje sin destrozarlo, sin aniquilar su carácter esencial, sin eliminar aquellos rasgos que le dan continuidad histórica, es uno de los dramas de nuestra civilización, como ya advirtió en 1925 Carl Sauer (Nogué y Albet 2004).
Por otra parte, en territorios donde se han superpuesto distintas culturas, o por el simple paso del tiempo, se impone el ciclo vital de la toponimia por el que surgen nuevos nombres (neotoponimia) junto a los que permanecen durante siglos y generaciones (paleotoponimia) aunque a menudo con importantes cambios que afectan su pronunciación y grafía; o que desaparecen (toponimia muerta) siendo sustituidos por otros que pragmáticamente identifican nuevas actividades y percepciones. Algunos autores lo atribuyen también a las limitaciones cognitivas de la mente ante la imposición de nuevas denominaciones que, si bien en una primera fase densifican el paisaje toponímico, a más largo plazo y después de una etapa de transición en que coexisten denominaciones paralelas, las obsoletas acaban en el olvido. De ahí la importancia de las fuentes escritas para recuperar aquellos nombres antiguos ya desaparecidos que permiten investigar el eje diacrónico del paisaje.

Respecto a la neotoponimia que caracteriza nuestros tiempos, destacan algunas actividades como principales promotoras: desde el turismo y sus infraestructuras hasta la urbanización difusa, la rururbanización (Ordinas y Binimelis 2002 y 2004) y la construcción de paisajes comerciales (commodified landscapes) que neotoponimizan casas rurales, urbanizaciones, etc. siguiendo modas y medios de comunicación y publicitarios que marcan las nuevas percepciones. Esta neotoponimia representa los cambios bruscos, rápidos y de difícil asimilación a los que aludía Eugenio Turri (1979) como principal problemática de la transformación intensa del paisaje, contrastando con las lentas y pacientes modificaciones del pasado. La agricultura intensiva, la industria, el turismo de masas y las grandes infraestructuras no han transformado el paisaje y su toponimia, sino que lo han destrozado y, en el mejor de los casos, homogeneizado (Nogué y Albet 2004). En el territorio balear, las nuevas percepciones surgidas a partir del impacto del llamado boom turístico como actividad que irrumpe a partir de los años 60 del siglo XX en una sociedad agraria tradicional cuya toponimia secular reflejaba el inmovilismo cultural, ahora pasarán a manifestar el cosmopolitismo que las nuevas actividades terciarias adoptan mediante nuevas denominaciones toponímicas que se implantan en las áreas urbanas litorales y que pretender asociar el lujo y glamur al negocio turístico mediante diversos recursos como el uso del inglés, la importación de exotopónimos y las alusiones a la luz y el color. 


\subsection{La PERCEPCIÓn del paISAJE A tRAVÉs de LA TOPONIMIA}

A través de la toponimia podemos percibir el paisaje al quedar descritos en ella sus elementos más característicos, pretéritos y actuales. Si, parafraseando a Darby (1957), «el conocimiento del territorio nos da las claves del significado de los nombres», podemos inferir que, inversamente, también a través de los nombres se obtiene el conocimiento del territorio. La abundante información que proporcionan los nombres geográficos, a veces oculta por el paso del tiempo y las transformaciones que acarrea, puede ser analizada y resulta de gran utilidad para la aprehensión del territorio. La toponimia no se limita a reflejar solo lo habitual, por abundante y repetitivo, característica que refleja el llamado principio de transparencia, sino también lo excepcional, por su rareza y el valor intrínseco que siempre conlleva y que constituye el principio de excepcionalidad.

El análisis geográfico del corpus toponímico y de los resultados obtenidos a partir de su clasificación y magnitud evidencian el cumplimiento del principio de transparencia, por el que los rasgos más característicos del paisaje, rural o urbano, quedan reflejados en la toponimia de forma sistemática. Por otro lado, también se detectan casos que se acercan a una mayor singularidad sin perder la significatividad territorial, de forma que incluyen los aspectos más relevantes de la geografía de una determinada región, aunque, a menudo, esta relevancia no es tan explícita al no contar con un importante apoyo numérico de topónimos, sino que exige un conocimiento y una interpretación por parte del observador del territorio al que se hace referencia (Tort 2003). El análisis de la toponimia permite constatar el cumplimiento de los principios de transparencia y de significatividad territorial que los investigadores de la toponimia, ya desde la escuela de Quebec (Poirier 1965), han aplicado a diversos territorios del planeta.

Asimismo, el análisis de los genéricos toponímicos y su frecuencia permite descubrir su correspondencia con los rasgos fundamentales del espacio donde se sitúan además de la terminología geográfica propia de cada territorio (Ordinas 2001). Y por supuesto, a través de la lectura diacrónica de la toponimia, podremos entender la evolución, los potenciales y las supervivencias del paisaje (Riesco 2010), eso es, el conocimiento histórico sumado al del terreno, o un suficiente mantenimiento del sentido original, permi- ten identificar sus significados paisajísticos y sus sencillas conceptualizaciones de los lugares. Martínez de Pisón (2010) afirma que la toponimia conduce a una reflexión sobre el paisaje al que da nombre, formando parte de su historia, y sobre la justificación de su empleo; lo que supone reabrir una puerta, tradicional y significativa, ocasionalmente olvidada.

\subsection{CUltura y COLOR: LA TEORÍA de BERLIN y Kay}

La dimensión cultural del color fue abordada por el antropólogo Brent Berlin y el lingüista Paul Kay de Berkeley, California, en su estudio sobre Términos básicos de color: Su universalidad y evolución (1969). En él propusieron que los términos básicos de color en una cultura son predecibles por el número de términos de color que tiene la cultura. Todas las culturas tienen términos para negro/oscuro y blanco/brillante. Si una cultura tiene tres términos de color, el tercero es rojo, y si son cuatro, incorpora amarillo o verde.

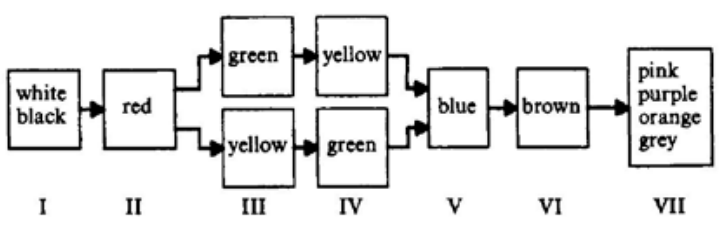

FiguRA 1.- Representación esquemática del orden de evolución de los términos básicos del color en la teoría de Berlín y Kay (1969). Fuente: Berlín y Kay (1969).

En conjunto, Berlín y Kay (Figura 1) establecen una secuencia de siete etapas de las culturas respecto a los colores que contienen, evolucionando desde la etapa I que tiene solamente los colores negro y blanco, a la etapa VII donde aparecen ocho o más términos básicos de color. A medida que los idiomas evolucionan, adquieren nuevos términos de color en una estricta secuencia cronológica, de manera que si un término de color básico se encuentra en un idioma, entonces los colores de todas las etapas anteriores también deben estar presentes. Aunque la teoría de Berlin y Kay ha logrado una influencia generalizada, las restricciones en el orden de los términos de color se han suavizado sustancialmente, tanto por los propios autores (Kay y McDaniel 1978) en publicaciones posteriores, como por varios críticos como Barbara Saunders, quien cuestionó las metodologías de recolección de datos y las suposiciones culturales que sustentan la investigación, así como Stephen C. Levinson. Efectivamente, tanto las fuentes de estudio como la complejidad de las culturas (Hardin 2013) permiten sembrar 
dudas razonables sobre la universalidad y simplicidad de la teoría que, no obstante, no deja de constituirse en el más importante referente antropológico en su temática.

En cualquier caso, la aplicación de la teoría de Berlin y Kay a la cromotoponimia de las islas Baleares permite obtener resultados significativos y acordes con el orden de las fases evolutivas de los términos básicos del color de la toponimia balear.

\section{OBJETIVOS, METODOLOGÍA Y FUENTES}

Nuestro trabajo aborda, por primera vez, el estudio de la cromotoponimia de las Islas Baleares, siguiendo una larga trayectoria de investigación en toponimia balear en la que pretendemos averiguar el grado de significación y presencia de la cromotoponimia como indicador del paisaje. Mediante una metodología extrapolable a otros territorios, se analizan las diferencias en el cromatismo entre las diferentes islas del archipiélago balear y su representatividad entre la toponimia mayor y la microtoponimia. Finalmente, se pretende analizar la jerarquía de los colores registrados en la toponimia.

La fuente de la cromotoponimia balear es una base de datos de unos 50000 topónimos fruto de la recolección toponímica realizada para el Mapa Topográfico Balear a escala 1:5000. Para ello, se utilizaron las principales obras cartográficas ${ }^{4}$ para localizar los topónimos e incrementar su densidad a partir de centenares de entrevistas realizadas sobre el terreno a otros tantos informadores, previamente seleccionados por su especial conocimiento del territorio. Se trata, por tanto, de un análisis que parte del corpus toponímico actual, aunque en la toponimia quedan fijados elementos de la realidad paisajística pretérita. De la toponimia almacenada en dicha base de datos se han extraído aquellos ejemplares alusivos al color para su posterior clasificación y análisis.

\section{EL CROMATISMO EN LA TOPONIMIA: DE COLORES SE VISTE EL PAISAJE}

Entre los rasgos del paisaje, destaca el color como uno de los principales y más llamativos a la hora de

4 Destaca el Mapa Topográfico Nacional de España (IGN) a escala 1:25.000. contemplarlo y describirlo, pues el ojo es atrapado por sus colores, como ya escribía Julio Verne (1892). Y aunque los nombres geográficos engañen -añadía-, la primera geografía, que es el paisaje, entra inevitablemente por la mirada (Martínez de Pisón 2010). La descripción cromática es uno de los factores referenciales básicos en que se fijan los creadores de topónimos. El colorido es una de las determinaciones preferidas al establecer el nombre de los lugares, pues en ocasiones se manifiesta como un rasgo muy visible y llamativo del terreno. $Y$ esto es así de manera universal e independientemente de la lengua en la que surjan los nombres (García Sánchez 2015). Así que las toponimias respectivas de cada zona geográfica pueden caracterizarse, entre otras cosas, por el color; y más que por la coloración del terreno, por las denominaciones cromáticas que el hombre aplica a la geografía, que no es exactamente lo mismo, puesto que esa nominalización resulta siempre de una valoración subjetiva (Trapero 1995). De hecho, el cromatismo del terreno, ya sea por su propia composición geológica, por la presencia de vegetación, o por la acción del hombre sobre el suelo, es uno de los elementos más a mano que el hombre tiene para denominar la geografía e individualizar un punto del terreno dentro de su entorno. Los adjetivos indicando el color de la tierra o de la roca se hallan frecuentemente en los nombres de lugar, aunque todas las diferencias remarcables del colorido no provienen únicamente del aspecto del suelo (Moreu-Rey 1982). Y tan importantes son los nombres de color en la toponimia que forman un grupo individualizado con denominación propia: cromotoponimia, aunque a veces esta ha sido enfocada solo desde una perspectiva filológica (García Arias 1980).

Según la zona geográfica, hay cromotoponimias opacas, uniformes, y las hay brillantes, multicolores; además de una variada gama de escalas intermedias. Naturalmente, el que sean de una modalidad u otra puede depender, en primer lugar, de la naturaleza geológica, pero también de la lengua, pues un mismo color puede tener diversos nombres que establecen matices y diferencias lingüísticas. En todas las lenguas existen el blanco y negro y, en el caso que haya tres, el tercero es el rojo (Català 1995).

Desde antiguo, el color ha llamado la atención de la población rural, aunque su paleta fuera más bien reducida: blanco, negro, rojo, verde, azul y alguna otra tonalidad. Pero no todos los colores tienen el mismo peso en toponimia. La cromotoponimia se da, sobre todo, con tonos que destacan sobre los demás 


\begin{tabular}{|l|c|c|c|c|c|c|}
\hline \multicolumn{1}{|c|}{ COLOR } & MALLORCA & $\%$ & MENORCA & $\%$ & PITIUSAS & \% \\
\hline Blanco (blanc, alb) & 112 & 28,9 & 80 & 40,4 & 23 & 18,3 \\
\hline Negro (negre, moreno, cremat, socarrat, cuina) & 89 & 23,0 & 31 & 15,7 & 34 & 27,0 \\
\hline Gris (gris, argent/plata) & 9 & 2,3 & 1 & 0,5 & 5 & 3,9 \\
\hline Rojo (roig, vermell, almangra, marrón) & 130 & 33,6 & 59 & 29,8 & 31 & 24,6 \\
\hline Verde (verd) & 25 & 6,4 & 16 & 8,1 & 23 & 18,3 \\
\hline Azul (blau) & 12 & 3,1 & 7 & 3,5 & 1 & 0,8 \\
\hline Amarillo (groc, or, ros) & 10 & 2,6 & 4 & 2,0 & 9 & 7,1 \\
\hline TOTAL & 387 & 100 & 198 & 100 & 126 & 100 \\
\hline
\end{tabular}

TABLA 1.- Distribución de la cromotoponimia balear. Elaboración propia.

y que, como es lógico, se puedan encontrar en el paisaje. Así, el blanco, por su fácil asimilación a lo luminoso y brillante, y el rojo, por su rápida visibilidad, son frecuentes en la toponimia española en sus distintas variantes léxicas y de expresividad de matices tonales (García Sánchez 2015). Todo ello no difiere del estudio realizado por Berlin y Kay (1969) sobre la universalidad y evolución del color.

Además, al ser la toponimia un registro histórico y no del todo sincrónico, refleja ciertos desajustes con el habla coloquial actual. Mientras perviven nombres en la toponimia que han dejado de usarse o con un bajo nivel de frecuencia en la lengua común -roig podría ser un buen ejemplo en la toponimia balear-, por otra parte, faltan o tienen una representación toponímica exigua, términos que son de uso común en la lengua actual -como es el caso del vermell en la toponimia del archipiélago-. Tampoco pasa por alto la representatividad o asociación de contenidos que conllevan algunos colores. Así, mientras el verde se relaciona con la vegetación (fitotoponimia), el azul con las masas de agua (hidronimia) y las diversas tonalidades del rojo con materiales líticos (geotoponimia) y, por ende, con las construcciones humanas -tal como refleja la simbología cartográfica-; otros colores se alejan de esta aparente y falsa univocidad y resultan de mayor polivalencia representativa. En definitiva, no ha de extrañar que una profusión de color constituya un factor decisivo a la hora de identificar un lugar y que pueda surgir una denominación toponímica a partir de ella (García Sánchez 2015).

\subsection{BLANCO Y NEGRO}

Además de opuestos, son dos de los tres colores más frecuentes en la toponimia. Berlín y Kay (1969) los sitúan en el primer nivel, el más básico, de la secuencia cronológica cultural. Su dualidad les convierte en un rasgo muy característico de la percepción que sobre la paleta de colores tiene el hombre y que así se refleja en la toponimia de las Islas Baleares.

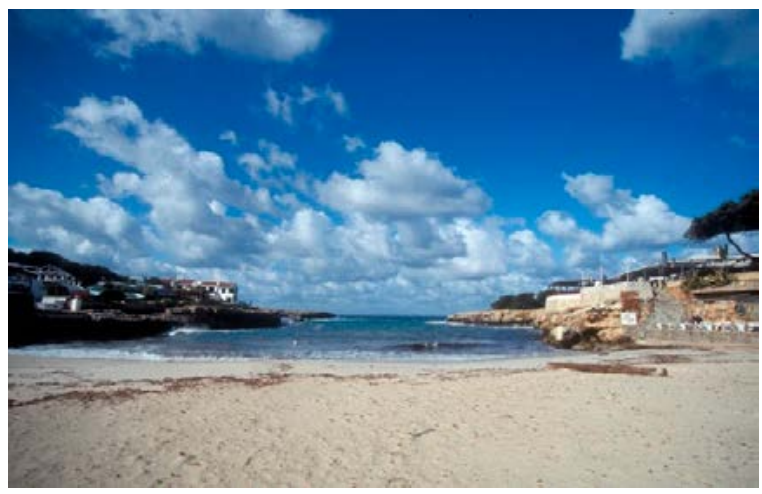

FigurA 2.- Cala Blanca (Ciutadella). Autoría: A. Ordinas.

Blanco es el color de la luz solar, no descompuesta en los colores del espectro. Simboliza la pureza y el duelo en algunas culturas, y está presente en la toponimia a través de numerosas adjetivaciones referidas a la coloración blanquecina de los materiales. En Baleares, lo encontramos en núcleos de población (s'Alqueria Blanca y sa Casa Blanca ${ }^{5}$ ) y en urbanizaciones turísticas (Ciudad Blanca, Aldea Blanca, y Cala Blanca) (Figura 2); aunque su aplicación geográfica puede ser muy diversa, a tenor de los genéricos que acompañan tanto al masculino blanc como al feme-

5 Nótese que la coloración va unida a la construcción (alquería, casa...) que da origen al topónimo, fundamentado en la antigua costumbre de encalar las fachadas. El hecho se repite en las urbanizaciones, donde genéricos como ciudad y aldea también son susceptibles de caracterizarse por el color blanco. 
nino blanca y sus respectivos plurales (blancs/blanques): Aljub Blanc, Barraca Blanca, Barrera Blanca, Bassa Blanca, Cala Blanca, Camí Blanc, Camp Blanc, Cap Blanc, entre otros muchos.

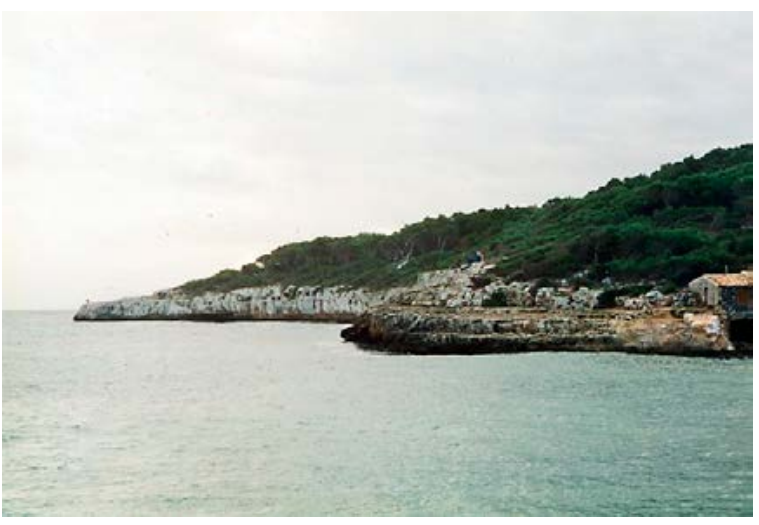

FiguRA 3.- Punta Blanquer (Santanyí). Autoría: A. Ordinas.

En su forma sustantiva, el blanco aparece como genérico talasonímico (Blanc de s'Àguila, es Blanc...), para designar un fondo arenoso que cubre tanto superficies extensas -como suele ocurrir delante de playas de arena- como pequeñas manchas rodeadas de alga o roca (Lucas y Ordinas 2013). También puede designar peñas de color blanquecino y terrenos donde abunda la arcilla denominados blanquers: ${ }^{6}$ es Blanquer, Roques des Blanquer, Pedra des Blanquer, Punta Blanquer (Figura 3)... aunque se llama también blanquer, un tipo de roca blanquecina, débil y fácil de desmenuzar.

Son numerosos los topónimos referidos explícitamente al blanco, con un total de 199 para el conjunto del archipiélago ( $28 \%$ de la cromotoponimia balear). Por islas, se observa la mayor presencia relativa en Menorca, seguida de Mallorca e Ibiza (Tabla 1).

Además, los cromotopónimos referidos al blanco presentan una gran diversidad de realidades geográficas -parajes, rocas, cabos y puntas litorales, islotes, cuevas, montes, calas, casas, etc.-. También aparece en topónimos arcaicos (Montblanc) o quizás antropotopónimos (Son Blanc, Can Blanc, Cas Blancos y Ca na Blanca); además de ejemplares donde la presencia antroponímica resulta evidente: Avenc d'en Blanc, Moli d'en Blanc y Coll de na Blanca. Curiosamente, también se adjetivan hidrónimos: Pou Blanc, s'Aigua Blanca y Font Blanca.

\footnotetext{
6 En Ibiza, blancar.
}

Aparecen algunos ejemplares cromotoponímicos asimilables al blanco, frente al cual, de la raíz germana blank, encontramos albus, de procedencia latina. Se trata de las referencias a albo/alba que solo localizamos en Menorca -en nombres aglutinados como Torralba, Torralbenc, Albaida y Vil.la Alba- y al único caso de Ibiza (Bisalba), que si se suman a los casos de blanco (Tabla 1), conjuntamente apenas alteran las proporciones por islas, si no es para aumentar ligeramente la diferencia en positivo de Menorca.

En cuanto al negro, desde el punto de vista conceptual, no representa un color determinado sino la falta de todo color y la ausencia de luz. En Baleares, los cromotopónimos a él referidos suman 106, lo que con un $14,9 \%$, le convierte en el tercer color toponímico, después del blanco y del roig. Su distribución por islas queda reflejada en la Tabla 1, donde destaca porcentualmente Ibiza.

Los topónimos que contienen el negro, casi siempre en forma adjetival, aluden a cavidades, cabos y puntas litorales, parajes, peñas, fuentes, islotes, calas, montes, valles, sierras, etc. Así, Puig Negre, Moleta Negra, Forat Negre, Punta Negra, Cap Negre, Terra Negra, Pujol Negre...

Curiosamente, también detectamos algunos hidrónimos (Font Negra y Cala Negra); plurales (Penyes Negres, Illetes Negres...) y diminutivos: Cap Negret (Figura 4), na Negrina... Incluso referidos a nombres de casa con origen en un antropónimo: Son Negre, Can Negre, Ca na Negreta...

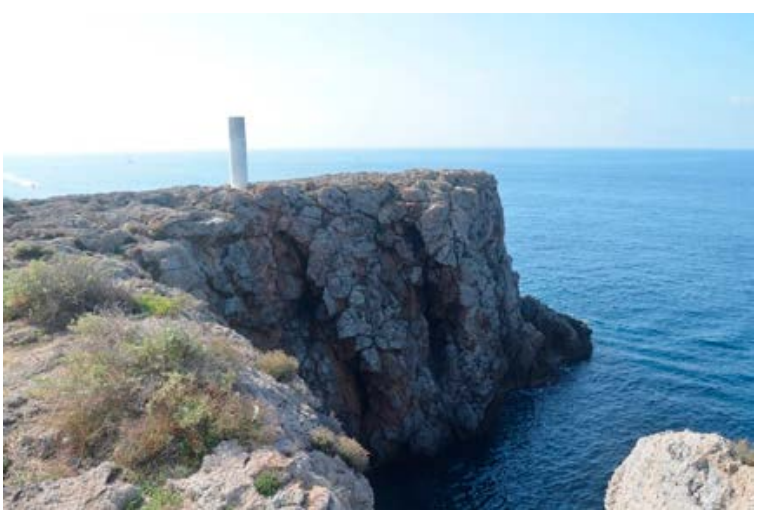

Figura 4.- Cap Negret (Calvià). Autoría: A. Ordinas.

Al igual que en Canarias (Trapero 1995), el término negre no se sustantiva en la toponimia balear, con la excepción de un genérico talasonímico. Con la denominación de negre, los pescadores hacen referencia a la superficie del fondo marino cubierta muy densa- 
mente por la Posidonia oceanica. En su interior, se pueden situar algunas zonas aisladas de escasa vegetación submarina (pelats) y arenosas (blancs), además de piedras (Lucas y Ordinas 2013).

Asociados al negro, existen otras gamas también presentes en la toponimia cuyo impacto numérico queda también reflejado en la Tabla 1 . Nos referimos tanto al adjetivo moreno/a (Figura 5), como a otros, muchas veces sustantivados, relativos a áreas donde se han producido incendios forestales de diversa extensión e impacto, fosilizados en la toponimia. Se trata de cremats/cremades/socarrats, lugares quemados por el fuego donde, por deslizamiento semántico, el color resultante de la combustión se convierte en rasgo definidor pertinente del topónimo. También las referencias a cuina/cuines (cocina/cocinas) van asociadas al negro.

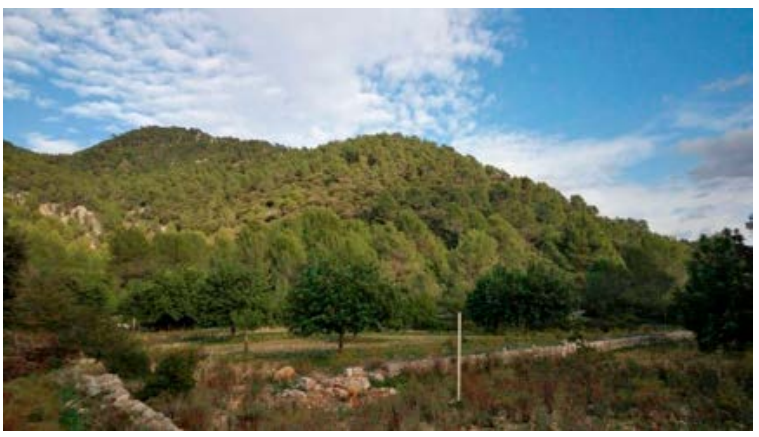

Figura 5.- Serra Morena (Mancor de la Vall). Autoría: A. Ordinas.

Respecto a las referencias a cremat/cremada, mayoritariamente situadas en Mallorca, destaca su escaso número (2,2 \%). Lógicamente suelen referirse a parajes como es Cremat, na Cremada, Corrals Cremats..., aunque también alude a incendios en edificaciones: Cudia Cremada Vella, Can Casa Cremada y a antropónimos de apodos: Can Cremat, Punta d'en Cremat.

El término socarrat $(2,1 \%)$ tiene un significado muy parecido, aunque con connotaciones de combustión vegetal de menor intensidad. Aparece el genérico masculino (es Socarrat), plural (es Socarrats) e incluso femenino (sa Socarrada). A veces se adjetiva ( $P u$ jol Socarrat, Torrent Socarrat...) y otras la apariencia es de antropónimo: Can Socarrat, Puig d'en Socarrat...

Los topónimos alusivos a cuina/cuines responden a la coloración oscura, ennegrecida, de las paredes rocosas que, por simple metáfora, se asocia a las cocinas antiguas sometidas a la acción del fuego y del humo, aunque realmente se debe a la presencia de líquenes. Solo en Mallorca se registran algunos ejemplares como sa Cuina, Cuina del Moro, Cuina del Bisbe, Comellar des Mal Cuinat, ses Cuines Velles... Y algo parecido sucede con el adjetivo moreno/a, cuya presencia toponímica se detecta en Mallorca y Menorca (Serra Morena, Cala Morena...).

\subsection{GRIS}

Sabido es que resulta de la mezcla de blanco y negro, y que se caracteriza en el habla por los semas "mediocre, poco destacado, triste y sin color», puestos de relieve en expresiones coloquiales como un hombre gris, un cielo gris, una imagen en blanco y negro frente a otra en color, etc. Por ello, es el no color por excelencia, difícil de precisar por lo poco destacado que resulta, el más propio y común del terreno $y$, en consecuencia, el menos nombrado en la toponimia, por lo ineficaz que resulta como identificador de un lugar.

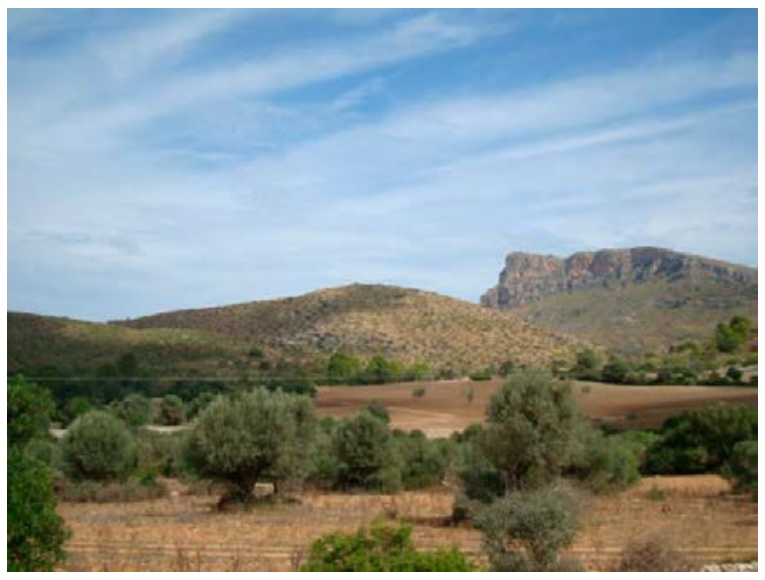

Figura 6.- Puig Gris (Artà). Autoría: A. Ordinas.

Solo unos pocos topónimos -Puig Gris (Figura 6), Serrat Gris...- aluden a dicho color. Asimismo, la ceniza (cendra) destaca por su color gris, hallando dos ejemplares de es Cendrer. Existe cierta similitud en los topónimos que aluden a la plata (argent), de forma que, en Ibiza, s'Argentera constituye el origen de otros topónimos derivados: Puig de s'Argentera, Torrent de s'Argentera, Pla de s'Argentera...; además de antropotopónimos como Can Mariano de s'Argentera, Can Pep de s'Argentera... En Menorca aparece Son Plata -posiblemente un auténtico descriptivo- y un exotopónimo (Estància Riu de la Plata) que, como tantos otros, tiene su origen en la emigración de la primera mitad del siglo XX. En Mallorca, más rica en 
ejemplares y formas, hallamos s'Argentera, Cova Argentera, s'Argentelar, Font de l'Argent, Puig de s'Argenter, Valldurgent...

\subsection{VERDE}

Su presencia toponímica en las Baleares ocupa un lugar relativamente destacado, con una cuarta posición en frecuencia - precedido por blanco, negro y rojo-, o una quinta si distinguimos entre vermell y roig, dos matices del color encarnado y ambos con frecuencia superior al verde que obtiene un $8,7 \%$ de la representación cromotoponímica. En la escala de Berlin y Kay (1969) puede aparecer ya en una tercera etapa cultural, disputando su presencia con el amarillo, o ya definitivamente en la cuarta.

El verde, en todas sus gamas, es el color vegetal, el color clorofílico y, por tanto, muy común en el paisaje donde la vegetación se hace omnipresente. De ahí quizás su discreto peso en la paleta cromática del paisaje. De acuerdo con la ley toponímica de la excepcionalidad, lo que es percibido como raro tiene muchas más posibilidades de quedar reflejado en la toponimia al convertirse en un hito o referente espacial destacado y fácilmente reconocible frente a todo aquello que es abundante en el territorio. En tal sentido, corrobora dicha hipótesis la distribución por islas (Tabla 1), donde se aprecia la mayor presencia del verde en lbiza con un paisaje comparativamente más árido que el resto del archipiélago y donde el verde es menos abundante. Sin embargo, el porcentaje de cromotopónimos alusivos al verde es significativamente mayor, duplicando a su competidora más cercana, Menorca, cuyo paisaje, a priori, debería encabezar la cromotoponimia verde.

De todo ello se infiere que en la toponimia isleña el verde no es tan frecuente como corresponde a su abundante presencia visual. Aun así, se registran ejemplares como es Tossals Verds, Puig Verd (Figura 7), Serra Verda, Cingle Verd, Pla Verd, Canal Verd, Punta Verda, Racó Verd, Caló Verd... y derivados como sa Verdera, ${ }^{7}$ sa Verdereta, Costa de ses Verdors, así como otros alusivos a una de las variedades de higuera denominada verdal, origen de topónimos como

7 Verdera proviene del latín viridaria, 'lugar verde de hierba o follaje'. sa Verdal, ses Verdals, Camp Verdal, Clot de ses Figueres Verdals, Tanca de na Verdal, na Verda, na Verdalosa... Finalmente, algunos neotopónimos como Montañas Verdes y Valverde designan urbanizaciones en las que la denominación toponímica ya forma parte de las nuevas percepciones asociadas a la especulación con los valores ecológicos y clorofílicos tan demandados por una población urbanita obsesionada por la verdolatría (Roger 2007).

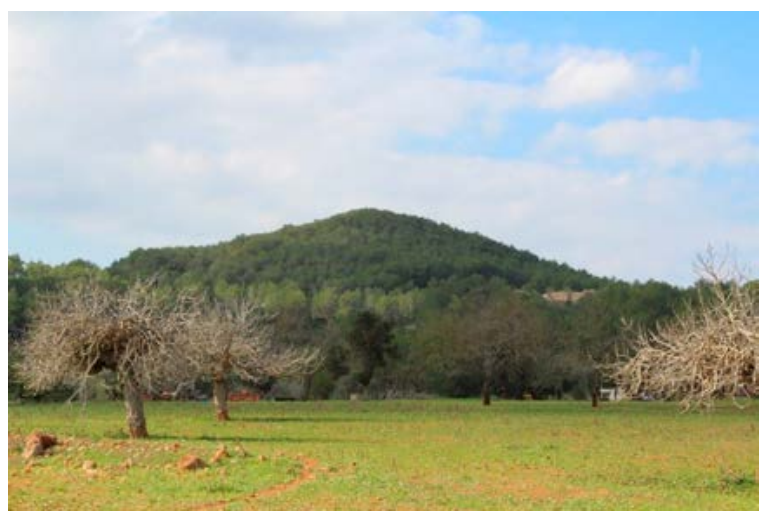

Figura 7.- Puig Verd (Sant Antoni de Portmany). Autoría: A. Ordinas.

\subsection{Rojo}

Hay quien sitúa el rojo como el primero de todos los colores, el color por excelencia, el color arquetipo, argumentando que en muchas lenguas rojo hace alusión a lo coloreado o colorado, "que tiene color», que por naturaleza o arte tiene color más o menos rojo (García Sánchez 2015). Berlin y Kay (1969) lo sitúan en la segunda etapa, después de la formada por el blanco y el negro.

El color rojo es, sin duda, el más llamativo de la gama cromática (el primero del espectro solar), y quizá por ello el que más lexicalizados tiene sus diferentes matices cromáticos en el lenguaje común que, en catalán, se refiere a él preferiblemente con el término vermell, aunque en toponimia es más frecuente la utilización del término roig, al igual que sucede en Cataluña y a diferencia, en cambio, de la región valenciana (Rosselló Verger 2004). No obstante, debemos matizar que esta jerarquía en esta escala dicotómica cromotoponímica (roig/vermell), aunque mayoritaria en el conjunto del archipiélago, presenta disparidades si se analiza por islas (Tabla 1). Mientras que en Mallorca e Ibiza predomina el roig, en Menorca prevalece el vermell. Su unión (roig+vermell) 
constituye el grupo cromotoponímico más frecuente (29,3 \%). Su contabilización por separado, en cambio, los reduce a un $17,3 \%$ y a un $12 \%$, respectivamente, sin contar las tonalidades asimilables como el almagre $(1,4 \%)$ y el marrón $(0,3 \%)$.

Adornados de rojo (roig), hallamos multitud de elementos geográficos, donde aparecen ambos géneros para designar formas de relieve como Penyal Roig, Penya Roja, Roca Roja, Puig Roig, Plana Roja, Coll Roig, Coma Roja, Cova Roja; y también relieve litoral: Cap Roig, Morro Roig, Cala Roja, Caló Roig, Racó Roig, na Roja, Punta Roja, Cala Penyes Roges. Asimismo, se aprecian algunos hidrónimos (Font Roja, Bassa Roja, Torrent Roig, Aljub Roig, Pou Roig, Font Rojal...), constatándose una vez más que no todos ellos reflejan una coloración azul. También fitotopónimos (sa Mata Roja, es Càrritx Roig...); campos de cultivo (Camp Roig, Tanca Roja, Cloves Roges, Terra Roja); además de construcciones (Camí Roig, Alqueria Roja, Torre Roja).

En el abundante repertorio cromotoponímico del roig, también aparecen referencias derivadas: la Rojal, Font Rojal; plurales: Penyes Roges, Cases Roges; y diminutivas: Ses Rogetes; además de aglutinaciones como Marroig -de Mas Roig-, Carrotja -de Casa Roja- o Porroig -de Port Roig-. Son asimismo descriptivos Son Roig, Son Roig Vell, Son Roig Bonico... y sus derivados: Puig de Son Roig.

Respecto al vermell, en la Tabla 1 se observa como, en su gama, es la denominación predominante en la toponimia menorquina, a diferencia de Mallorca y Pitiusas.

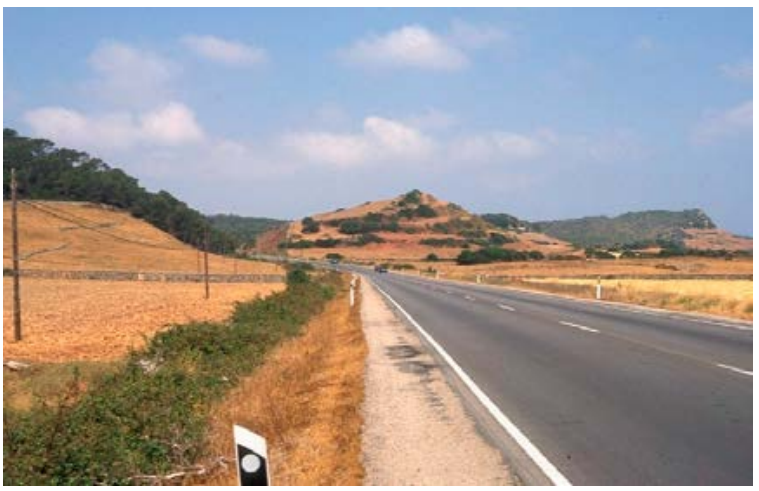

Figura 8.- Pujol Vermell des Coll Roig (Ferreries). Autoría: A. Ordinas.

En cualquier caso, su abundancia también refleja su aplicación a gran diversidad de accidentes orográficos: Cap Vermell, Punta Vermella, Penyal Vermell, Pedra Vermella, Puig Vermell..., pero no así a los hi- drográficos, donde no aparece, y raramente en los fitotopónimos (es Morer Vermell). También está presente como color de materiales del suelo: Terra Vermella, Terres Vermelles, es Call Vermell, ${ }^{8}$ Pujol Vermell des Coll Roig ${ }^{9}$ (Figura 8), Pleta Vermella; y de construcciones: Torre Vermella, Far Vermell, Creu VermeIla. Son relativamente abundantes los topónimos donde aparece la sola denominación del color sin ningún genérico acompañante: en Vermell, es Vermell, el Vermell, es Vermells, na Vermella, ses VermeIles, Vermell de s'Ou... También aparece en Son Vermell -siempre en la duda de su origen descriptivo o antroponímico- y en otros claramente antroponímicos (Can Vermell, Molí de Can Vermell...).

Asociadas a la coloración rojiza van las escasas referencias toponímicas al almagre -Comellar de s'Almangra, Cova de l'Almangra, Vénda de s'Almangra, Coll de s'Almangra-, solo presentes en Mallorca e Ibiza. El término es un arabismo con el que se designa una tierra de coloración ocre rubicundo ${ }^{10}$ al tratarse de peróxido de hierro aluminoso, mezcla natural de alúmina y tierra rica en óxido de hierro.

\subsection{AzUL}

En Baleares, comúnmente se utilizan dos nombres para designar distintos tonos del azul: cel (azul claro o celeste), y blau que designa el azul por antonomasia, un azul más oscuro o marino. Solo esta segunda fórmula aparece en la toponimia balear con un modesto 2,8 \%. Esta discreta representación concuerda con la secuencia cronológica de Berlin y Kay (1969) que sitúa al azul en una evolucionada quinta etapa cultural, donde las sociedades ya han asimilado previamente blanco, negro, rojo, amarillo y verde.

Entre otras simbologías, el azul representa, en la tradición cartográfica, la presencia del agua y de ahí que también en toponimia se rotulen en azul los hidrónimos. No obstante, no todos los cromotopóni-

8 Nombre que en Mallorca recibe la tierra de labor formada por suelos rojizos ricos en óxido de hierro, también denominada terra rossa.

9 Además de un doble determinante, el topónimo incluye las dos denominaciones del rojo, acentuando la relevancia del color como elemento paisajístico, resultado de la abundante presencia del óxido de hierro.

10 Tradicionalmente, los pastores isleños aplican una mezcla de almagre y aceite sobre las ovejas como repelente de las moscas. 
mos referidos al azul se corresponden con hidrónimos, aunque algunos se amoldan a este estereotipo y se localizan en el litoral, focalizando la coloración azul de sus aguas, muchas veces utilizada con fines claramente turísticos, como en la mítica Costa Azul francesa. En la misma línea de costa o en sus proximidades, detectamos nombres como Cala Blava, ${ }^{11}$ Blau del Toro, Badia Blava, ${ }^{12}$ Cova Blava, ${ }^{13}$ na Blava, Mar Blava, ses Aigües Blaves... También hidrónimos, aunque de interior, son el Gorg Blau, Pou Blau y Torrent de Cala Blava. También de interior, pero no hidrónimos, son Pedrera Blava, Barrera Blava, sa Capella Blava, ${ }^{14}$ s'Aigua Blau, sa Casa Blava... El blau tampoco está exento de la duda entre descriptivos o antropónimos en casos como los de Son Blau, Son Blauet, Can Blau...

Respecto a la distribución por islas, en la Tabla 1 se observa el mayor peso relativo en Menorca, seguida de Mallorca e Ibiza, donde su presencia es testimonial.

\subsection{AMARILLO}

En la toponimia balear la suerte del amarillo parece escasa, a tenor del 0,5\% de presencia testimonial. En la Tabla 1 se observa su ausencia en las Pitiusas y un único ejemplar en Menorca: Cova na Grogueta. En Mallorca hallamos los genuinos Caló Groc y na Groga, además del dudoso descriptivo Son Groc. De origen antroponímico parecen ser Can Groc, Ca na Groga, Puig de Can Groc, Hort d'en Groc, Puig de na Groga, Rafal d'en Groc... Tal escasez no concuerda con la escala de Berlin y Kay (1969) donde el amarillo puede aparecer en la tercera etapa evolutiva y se consolida en la cuarta. Probablemente la explicación resida en el escaso uso del término groc frente a otros que en el archipiélago balear pueden serle asimilados, como es el caso de la coloración dorada y ros (rubio), también detectado como color que aparece

11 Neotopónimo ya clásico que sustituyó al genuino Cala Mosques, considerado poco adecuado por los promotores de la urbanización.

12 Neotopónimo relativo a una urbanización litoral del municipio de Llucmajor.

13 Situada en la costa de Cabrera y famosa por la belleza y coloración azul de sus aguas por efecto de la iluminación solar. Neodenominada Cueva Azul, al imponerse la publicidad turística de los cruceros que la visitan.

14 Junto con s'Aigua Blau son nombres de montes. en la toponimia de la comunidad valenciana (Català 1995). En cuanto a la primera, solo unos pocos ejemplares localizados en Mallorca hacen referencia al oro: sa Copa d'Or, una metáfora relativa a una sementera, no sabemos si por su excelente productividad agrícola o por sus antiguos trigales; así como el Clot de l'Or, con elevadas probabilidades de una explicación similar. No es el caso de Cala d'Or, urbanización iniciada en 1933, cuya denominación supuso la aparición de uno de los primeros neotopónimos asociados a la naciente actividad turística de la isla. Finalmente, cabe señalar el Dorado, topónimo hoy decadente, que también designó una urbanización costera de finales de los años sesenta. Al igual que en Mallorca, en otros territorios peninsulares también detectamos neotopónimos relativos al oro y al color dorado como símbolo de lujo y glamur asociado, mediante el nombre, a lugares turísticos que pretenden destacar sobre la toponimia tradicional.

Más abundantes que el propio amarillo resultan, en cambio, las alusiones al ros/rossa (rubio/a), presentes en todas las islas, aunque en Ibiza y Menorca apenas reúnan una exigua representación. En la pitiusa mayor sa Sal Rossa, uno de los estanques de sus históricas salinas, da nombre, por derivación, a toda una serie de lugares cercanos: Camí de sa Sal Rossa, Puig de sa Sal Rossa, Torre de sa Sal Rossa, Illa de sa Sal Rossa, Estany de sa Sal Rossa... En Menorca se halla la Serra Rossa junto a un antroponímico (Son Rossó) y un derivado (Carreró de Son Rossó). En Mallorca, por último, junto a una enigmática $s a$ Caragola Rossa y unos posibles descriptivos como Son Ros y So na Rossa, abundan los antroponímicos: Can Ros, Can Rosset, Cas Rossos, Castell d'en Ros...

\subsection{OTROS}

Este apartado pretende ser un cajón de sastre en el que se traten aquellos cromotopónimos alusivos a colores hasta ahora inéditos en la austera paleta del paisaje balear. En la escala cromática de Berlin y Kay (1969), el marrón no aparece hasta la sexta y penúltima etapa evolutiva, mientras que otros colores como el rosa, el naranja, el gris o el púrpura se reservan a la última y más evolucionada de las etapas. De ahí que resultaría lógicamente extraño que el color rosa apareciese en la toponimia tradicional, tanto por tratarse de un color poco habitual en el paisaje natural como en la percepción de una población mayoritariamente agraria, poco acostumbrada a la sofis- 
ticación que simboliza dicho color. Sus costumbres se hallaban más bien en las antípodas de una vida cómoda y fácil como la que sugiere el estereotipo «de color de rosa». De ahí que las alusiones cromotoponímicas al rosa, además de escasas, correspondan a neotopónimos de origen urbanístico alejado del tradicional mundo rural. Se trata de topónimos metafóricos como la Pantera Rosa y Fresas con Nata en los que se evidencia la coloración predominante o presente en las edificaciones o urbanizaciones que designan, en el contexto de un municipio tan turístico y terciarizado como el de Calvià y donde la percepción que mediatiza la creación de neotopónimos responde a los mecanismos culturales de la sociedad moderna.

Son Pardo, Son Marron y Binimorat, aunque sugerentes, resultan falsos cromotopónimos. Entre las alusiones toponímicas al color naranja (taronja) destaca sa Taronja o Morro de sa Taronja, una peña de color anaranjado situada en la costa de Escorca. Asimismo, algunos ejemplares toponímicos alusivos a calabaza (carabassa) como Cap de sa Carabassa, Morro de sa Carabassa, Coll de sa Carabassa, sa Carabassa... podrían hacernos pensar en el color. Siguiendo la explicación proporcionada por el lingüista Álvaro Galmés de Fuentes (1990) quien, aplicándolo a otros topónimos parecidos, señala que existe en catalán antiguo el verbo crebar, derivado de la raíz prerománica kar"piedra», con el significado de "partir, agrietar». De esta forma, dichos topónimos procederían del derivado crebassa (corte, grieta) que, por epéntesis, se convierte en carabassa. En cualquier caso, por tanto, nada que ver con el fruto de la cucurbitácea, a pesar de la posible etimología popular.

Las alusiones toponímicas al color de las piedras preciosas como la esmeralda, el rubí u otras son prácticamente inexistentes si excluimos las denominaciones comerciales de establecimientos turísticos o neotopónimos invasores: Hotel Esmeralda, Cala Esmeralda. La presencia de rubí en la toponimia menorquina -Son Rubi, Rafal Rubí Nou, Rafal Rubí Vell, na Rubina, Caleta des Rubins- se debe al carácter antroponímico, al ser apellido.

\section{CONCLUSIONES}

En el caso de las Baleares no resulta fácil dar una cifra exacta sobre el número de cromotopónimos debido a los abundantes topónimos en que las referencias a colores aparecen precedidas del artículo pronominal (en, na), delator de un antropónimo, por lo que no pueden ser considerados auténticos cromotopónimos. Algo parecido sucede cuando los colores van precedidos por partículas, muy abundantes en la toponimia balear, como Son y Can (junto con sus variantes femeninas y plurales: So na, Ca na, Ca sa, Ca ses). Tales descartes reducen un buen número de los potenciales cromotopónimos, dando lugar a una cifra de 711 , lo que supone una densidad media de 0,14 cromotopónimos $/ \mathrm{km}^{2}$ y un 1,4\% del conjunto de la toponimia balear. En la distribución de la cromotoponimia por islas se constata la mayor presencia en Mallorca $(54,4 \%)$, seguida de Menorca $(27,8 \%)$ y las Pitiusas $(17,7 \%)$.

En la Tabla 1 se aprecia la distribución por colores y denominaciones de la cromotoponimia balear registrada. Las 18 denominaciones cromotoponímicas detectadas en la toponimia balear son:

a) Blanco y albo, que en el conjunto de la cromotoponimia balear suponen un $30,2 \%$. El blanco lidera el grupo con un $28 \%$ de los cromotopónimos, lo que le convierte en el color más frecuente de la toponimia.

b) Negro, moreno, quemado (cremat y socarrat) y cocina (cuina), forma metafórica de referirse a una coloración también oscura. En conjunto suman un $21,7 \%$, lo que les convierte en el tercer grupo. Entre ellos destaca el negro, con el 14,9 $\%$ de cromotopónimos, y también el tercero numéricamente.

c) Rojo (roig), bermellón (vermell), almagre y marrón forman otro grupo cromático que suma un 31 \% de los cromotopónimos, superando al grupo encabezado por el blanco. En él destaca el roig, con un $17,3 \%$, el segundo después del blanco, aunque también es remarcable el vermell, con un $12 \%$ de cromotopónimos. ${ }^{15}$

d) El verde, sin más variaciones terminológicas, reúne el $9 \%$ de los cromotopónimos, ocupando un quinto lugar en cuanto a frecuencia.

e) El azul -referido siempre como blau- aparece en un $2,8 \%$ de los cromotopónimos, cifra muy discreta que aun así supera la de los cromotopónimos referidos a alb, cremat, socarrat, ros y argent.

15 La jerarquía encabezada por el blanco y el rojo se halla también en la cromotoponimia canaria. Afonso (1988) afirma que «la cromotoponimia, con más de 400 registros con referencia al color, dominando el Blanco o su femenino; le sigue en orden el Rojo o Colorado». 
f) El amarillo -color secundario en todos los aspectos-, junto al oro (or) y rubio (ros) suman un 3,2 $\%$, destacando la frecuencia de ros que encabeza el grupo con un 2,1\%.

g) El gris, junto a las referencias a argent y plata que suman un $2,1 \%$.

Las anteriores denominaciones cromotoponímicas pueden resumirse en una paleta básica formada por 6 colores. Se trata de los colores primarios -rojo, verde y azul- a los que se suma el amarillo que, a pesar de secundario, es quizás el más notorio. A ellos se añaden el blanco y el negro, científicamente no considerados como auténticos colores, sino como la luz -el blanco como suma de todos los colores- y la oscuridad -el negro como ausencia de luz y, por tanto, de color-.

Como resultado de la aplicación del cociente de localización, se obtiene la Tabla 2 cuyos resultados, cuando son superiores a 1 , indican la significatividad obtenida por los respectivos colores en cada isla.

\begin{tabular}{|c|c|c|c|}
\hline COLOR & MALLORCA & MENORCA & PITIUSAS \\
\hline blanc & 1,03 & 1,17 & 0,624 \\
\hline alb & 0 & 3,37 & 0,353 \\
\hline negre & 0,97 & 0,78 & 1,437 \\
\hline roig & 1,3 & 0,47 & 0,918 \\
\hline vermell & 0,71 & 1,82 & 0,597 \\
\hline verd & 0,72 & 0,9 & 2,028 \\
\hline blau & 1,1 & 1,26 & 0,282 \\
\hline groc & 1,38 & 0,9 & 0 \\
\hline marró & 1,84 & 0 & 0 \\
\hline gris & 1,84 & 0 & 0 \\
\hline moreno & 0,31 & 2,99 & 0 \\
\hline cremat & 1,49 & 0,22 & 0,705 \\
\hline socarrat & 0,98 & 0,48 & 1,881 \\
\hline cuina & 1,84 & 0 & 0 \\
\hline almangra & 1,47 & 0 & 1,129 \\
\hline $\begin{array}{c}\text { argent/ } \\
\text { plata }\end{array}$ & 0,99 & 0,28 & 2,17 \\
\hline $\begin{array}{c}\text { Or } \\
\text { ros }\end{array}$ & 1,84 & 0 & 0 \\
\hline & 0,37 & 0,72 & 3,386 \\
\hline
\end{tabular}

Tabla 2.- Cromotoponimia de las Islas Baleares. Cociente de localización. Elaboración propia.

Dichos resultados permiten establecer una jerarquía de los colores con mayor representatividad en la cromotoponimia de cada isla. Si se ponderan junto con la mayor frecuencia, en el caso de Mallorca destacan el roig y el blanc. En Menorca, el vermell, el blau y el blanc. Y en Pitiusas, el verd y el negre. En cambio, entre los que aparecen con menor frecuencia, destaca la significatividad del groc en Mallorca, así como del gris, cuina, or, cremat y almangra; del $a l b$, moreno y blau en Menorca; y del ros, argent y socarrat en Pitiusas.

Por otra parte, cualitativamente, el paisaje y la toponimia comparten como común denominador el importante papel que juega la percepción en su conceptualización y análisis. La toponimia supone la expresión de conceptos territoriales claramente relacionados con el espacio o lugar habitado. En realidad, la toponimia es la forma de conceptualizar de una manera sencilla, para comprender el medio y la naturaleza con todas sus propiedades. A través de la Geografía de la Percepción se reincorpora la toponimia a los estudios geográficos, pues la percepción del espacio no puede separarse del aspecto general de la percepción humana, que tiende a organizar los objetos percibidos en categorías y expresiones, recordando que el espacio es algo vívido y vivido (Afonso 1988).

La toponimia permite descubrir el paisaje, actual e histórico, al ser parte de la historia de un paisaje, ya que no solo refleja los elementos predominantes, sino también los que ya han perdido la referencia original. $Y$ entre las múltiples informaciones y cualidades que los topónimos proporcionan se halla también el color. Hemos constatado que en la toponimia tradicional los cromotopónimos no son abundantes ni del todo escasos, fijando su cuantificación y proporción en las Islas Baleares. Y aunque la ausencia de otros estudios paralelos aplicados a otros territorios no nos permite aún la realización de análisis comparativos, la relativa escasez de la cromotoponimia nos permite aventurar, de modo general, que en bastantes casos su presencia obedece al principio de excepcionalidad, aunque el carácter descriptivo de la coloración tampoco nos permite descartar la aplicación del principio de significatividad territorial en aquellos cromotopónimos meramente descriptivos de la realidad que designan. No obstante, comprobamos que los colores que aparecen en la toponimia no están exentos de una gran dosis de subjetividad, pues con cierta frecuencia no reflejan la realidad de forma fidedigna sino mediatizada por su percepción.

Desde la perspectiva de un análisis cualitativo, constatamos la pobreza de la paleta cromotoponí- 
mica tradicional. Tal como señalan diversos autores analizando la cromotoponimia de la comunidad valenciana (Català 1995), del archipiélago canario ${ }^{16}$ (Trapero 1995) y de Mallorca (Llull 2004), resulta característica común la simplificación en el uso de los colores, utilizando solo aquellos más conocidos, sin apenas matices. Ello supone no superar, a lo sumo, la quinta etapa, sobre un total de siete, de la escala cultural cromática de Berlin y Kay (1969). Y si analizamos con detalle los porcentajes cromáticos (Tabla 3), la preponderancia de rojo, blanco y negro lo retrotraen hasta la segunda etapa evolutiva característica de una toponimia antigua y tradicional propia de una cultura agraria de origen medieval. Ello concuerda con la opinión de Pastoureau (2008), historiador experto en cromatismo medieval, quien explica que el concepto dicotómico blanco/negro que actualmente prevalece, es reciente en la historia de la humanidad y surge en la Edad Moderna, tras la invención de la imprenta, cuando la estampación de tinta negra sobre papel blanco -negro sobre blanco- empareja estos colores. Antes de constituirse esta asociación cromática, el antagónico al blanco era el rojo, siendo ambos los principales colores de la percepción social.

\begin{tabular}{|c|l|c|c|}
\hline \multirow{2}{*}{ Color } & \multicolumn{1}{|c|}{ Denominaciones } & \multicolumn{2}{c|}{ Cromotopónimos } \\
\cline { 3 - 4 } & $\begin{array}{c}\text { Porcentaje } \\
\%\end{array}$ & Número \\
\hline & $\begin{array}{l}\text { roig (rojo), vermell (rojo } \\
\text { bermellón), almangra } \\
\text { (almagre) y marró } \\
\text { (marrón) }\end{array}$ & 30,9 & 220 \\
\hline & $\begin{array}{l}\text { blanc (blanco) y alb } \\
\text { (albo) }\end{array}$ & 30,2 & 215 \\
\hline $\begin{array}{l}\text { negre (negro), moreno, } \\
\text { cremat y socarrat } \\
\text { (quemado) y cuina } \\
\text { (cocina) }\end{array}$ & 21,7 & 154 \\
\hline $\begin{array}{l}\text { verd (verde) } \\
\text { groc (amarillo), ros } \\
\text { (rubio), or (oro, dorado) }\end{array}$ & 3,2 & 23 \\
\hline & blau (azul) & 2,8 & 20 \\
\hline & gris (argent/plata) & 2,1 & 15 \\
\hline
\end{tabular}

Tabla 3.- Ranking de la cromotoponimia balear. Elaboración propia.

16 «La gama de colores base del arco iris, referente universal del que se parte en la identificación de los colores, puede simplificarse en la toponimia, como ocurre en la cromotoponimia grancanaria, donde se excluyen los colores anaranjado y violado» (Afonso 1988).
García Sánchez (2015) confirma que no todos los colores tienen el mismo peso en toponimia y que la cromotoponimia se da, sobre todo, con colores que destacan sobre los demás y que, como es lógico, se puedan encontrar en el paisaje. Así, el blanco, por su fácil asimilación a lo luminoso y brillante, y el rojo, por su rápida visibilidad, son colores frecuentes en la toponimia en sus distintas variantes léxicas y de expresividad de matices tonales. También la etiología surge con facilidad: será suficiente un tenue rojizo para que se denomine Puig Roig; o una coloración ligeramente más blanquecina que lo normal para tener un Cap Blanc.

Por el contrario, en la neotoponimia, de naturaleza turística y urbanizadora especialmente en Baleares, es donde proporcionalmente encontramos, además de un buen número de cromotopónimos, una mayor diversidad $y$, sobre todo, sofisticación en la gama de colores registrados, alcanzando cualitativamente la última etapa evolutiva de Berlin y Kay (1969), aunque la escasez de cromotopónimos innovadores solo permita hablar de tendencia. Fruto de nuevas mentalidades y percepciones, y en sintonía con los nuevos usos turísticos, especialmente localizados en el entorno urbano y litoral, la neocromotoponimia integra de forma significativa la belleza del paisaje de la que forma parte el color. Su paleta, más moderna y atrevida, incluye colores tradicionales, pero que responden a nuevas motivaciones como el verde asociado a los valores ecológicos y mentes clorofílicas, el azul -icono de aguas costeras mediterráneas-e incluso el blanco -símbolo también de construcciones litorales bajo la intensa luz estival-; a los que se añaden, con un plus de glamur, el rosa y algunos metales y piedras preciosas: oro, dorado, esmeralda... En la cromotoponimia tradicional, en cambio, no aparecen anaranjados, violáceos ni morados, pero sí otros antiguos cromotopónimos, como es Marroig, Porroig y sa Carrotja que, camuflados en su aglutinación, pasan mayoritariamente inadvertidos.

El avasallador predominio de solo tres colores que suman el 82,8 \% de los cromotopónimos baleares, evidencia la simplicidad de la paleta cromática de la toponimia tradicional, así como su carácter conservador que refleja la percepción de un paisaje que ha registrado menos cambios entre el siglo XIII y mediados del XX que a partir de esta última fecha. En este reciente período se han producido importantes y numerosos cambios en el paisaje como resultado del impacto de nuevas actividades terciarias -entre las que 
destaca el turismo y sus infraestructuras-, que suponen la aparición de una neotoponimia acorde con la nueva realidad y en la que se incluye una incipiente neocromotoponimia donde también se refleja la nueva percepción, con incorporación de nuevos colores que enriquecen la paleta. Así pues, los cromotopónimos no forman un conjunto caótico y caprichoso sin ninguna organización, sino que, por el contrario, se estructuran en pequeños conjuntos léxicos funcionales gobernados por oposiciones semánticas (blanc/negre, roig/vermell). La riqueza léxica de la cromotoponimia depende de la lengua funcional en que se expresa, de forma que no sirven aquí las clasificaciones universales, pues cada cromotoponimia local constituye un conjunto léxico propio, organizado semánticamente también de manera particular.

Desde el punto de vista morfológico, el color se lexicaliza en la toponimia balear mayoritariamente a través de adjetivo, aunque, al igual que sucede en Gran Canaria (Trapero 1995), los colores más comunes se sustantivan con cierta frecuencia por lo que se constata la facilidad y frecuencia con que el nombre de un color, que empieza siendo morfológica y funcionalmente un adjetivo, se convierte en la toponimia en un sustantivo.

Respecto a la simbología de los colores aplicada a la cromotoponimia, aunque no es posible establecer de forma general una clara correspondencia entre un color y un determinado tipo temático de topónimos o accidentes geográficos, se aprecian, no obstante, algunas tendencias a pesar de sus abundantes excepciones. Entre el conjunto de cromotopónimos predominan los orónimos a los que se aplican diversidad de colores, aunque el blanco, el rojo y el negro son los más frecuentes en su designación. Por otra parte, dos colores destacan por su mayor y más diáfano valor icónico. Se trata del azul y del verde. El primero, escaso en cuanto a número, se asocia mayoritariamente -aunque no exclusivamente- a hidrónimos de acuerdo con una clásica convención simbológica. En el archipiélago balear, las grandes masas de agua marinas ofrecen una amplia gama cromática de azules e incluso de verdes. A este último, por su parte, le sucede algo parecido, pues tradicional y simbólicamente se asocia a la flora. Sus cromotopónimos generalmente incorporan o añaden el valor semántico de la vegetación a través del adjetivo cromático en unos topónimos, mayoritariamente orónimos, que, de esta forma, complementan la identificación del genérico toponímico con la presencia, actual o pretérita, de una capa vegetal, sin mayor especificación.

El blanco, a pesar de su polivalencia cromotoponímica, se asocia en muchos casos a construcciones humanas, tradicionalmente encaladas y especialmente características del paisaje mediterráneo de las islas Pitiusas y de Menorca. El negro, por su parte, destaca como efecto del fuego, a veces real (como reflejan genéricos como cremat, socarrat), en otras percibido erróneamente a través de metáfora como producto de la combustión (cuina). En la cromotoponimia del rojo, sobre todo el roig, destacan claros ejemplos de orónimos que se explican por la presencia del óxido de hierro.

Finalmente, se debe advertir sobre la presencia de un numeroso grupo de falsos cromotopónimos, pues sus alusiones al color verdaderamente corresponden a antropónimos -apellidos y apodos- que forman antropotopónimos y que, por tanto, no son descriptivos respecto al color. No obstante, en ocasiones surge la duda cuando se trata de la partícula Son que precede el nombre de un color, pues podría corresponder tanto a un antropónimo como a un descriptivo, aunque la más probable sea la primera opción. $Y$ es que la estrecha relación entre apodos -en las islas denominados malnoms o noms de casa- o apellidos con lugares de denominación homónima dificulta la distinción sobre quién fue el origen de quien, de manera que quizás el antropónimo pueda provenir del topónimo o, al revés, sea el nombre del lugar el que adopte el nombre de un personaje histórico, frecuentemente anónimo, que pudiera haberse establecido en el lugar.

En cualquier caso, la cromotoponimia se constituye en un claro referente del análisis del paisaje contribuyendo al conocimiento de su percepción y de la etiología toponímica mediante uno de los rasgos cualitativos más destacados de la sensibilidad humana como es la visión en color.

\section{BIBLIOGRAFÍA CITADA}

Afonso, Leoncio. 1988. La toponímia como percepción del espacio. Los topónimos canarios. La Laguna: Instituto de Estudios Canarios. Universidad de la Laguna.

Berlin, Brent y Paul Kay. 1969. Basic color terms: Their universality and evolution. Berkeley: University of California Press.

Català, Pere. 1995. "Els colors a la toponímia», en Josep Lacreu (dir.), Materials de Toponímia, II: 1089-1096. València: Ed. Denes. 
Claval, Paul. 1995. La geographie culturelle. París: Nathan editions.

Darby, H. C. 1957. «Place names and geography». The Geographical Journal 123(3): 387-392. doi:< https://doi.org/10.2307/ 1791427>.

Dorion, Henri. 1986. «La toponymie et l'enseignement de la Geógraphie». Cahiers de geógraphie du Québec 30(81): 429-432. doi: <https://doi.org/10.7202/021817ar>.

Galmés de Fuentes, Álvaro. 1990. Toponimia de Alicante (La oronimia). Alicante: Universidad de Alicante.

García Arias, Xosé LLuis. 1980. «De toponimia tebergana (IV). Cromotoponimia». Boletín del Real Instituto de Estudios Asturianos 101: 645-654.

García Sánchez, Jairo Javier. 2015. "Lo que se verá a mi vera de Vera. Probable etimología vera del apelativo y topónimos homónimos». Quaderns de Filologia. Estudis Lingüístics XX: 229-249. doi: <https://doi.org/10.7203/qfilologia.20.7520>.

Hardin, C. L. 2013. "Berlin and Kay Theory», en Encyclopedia of Color of Science and Technology. Nueva York: Springer. doi: <https://doi.org/10.1007/978-3-642-27851-8_62-2>.

Hunn, Eugene. 1994. "Place-Names, Population Density, and the Magic Number 500». Current Anthropology 35(1): 8185. doi: <https://doi.org/10.1086/204245>

Kay, Paul y Chad K. McDaniel. 1978. "The linguistic significance of the meanings of the basic color terms». Language 54(3): 610-646. doi: <https://doi.org/10.2307/412789>.

Llull Martí, Antoni. 2004. "Els colors en els topònims», en H. Planisi y M. Rosselló (coords.), Sobre Onomàstica. Jornades d'Antroponímia i Toponímia (1993-2002): 91-96. Palma de Mallorca: Universitat de les Illes Balears.

Lucas, Antoni Miquel y Antoni Ordinas. 2013. «Mapes mentals, geolingüística i talassonímia en el Migjorn de Mallorca». Scripta Nova XVII(434). Disponible en: <http://www.ub.edu/ geocrit/sn/sn-434.htm>

Martínez de Pisón, Eduardo. 2010. "Valores e identidades», en Eduardo Martínez de Pisón y Nicolás Ortega Cantero (eds.), El paisaje: valores e identidades: 11-45. Madrid: Ediciones de la Universidad Autónoma de Madrid.

Moreu-Rey, Enric. 1982. Els nostres noms de lloc. Palma de Mallorca: Ed. Moll.

Nash, Joshua. 2015. «Island Placenaming and Insular Toponymies». Names 63(3): 146-157. doi: <https://doi.org/10.117 9/0027773815z.000000000110>.

Nogué, Joan y Abel Albet. 2004. "Cartografía de los cambios sociales y culturales», en J. Romero (coord.), Geografía Humana. Procesos, riesgos e incertidumbres en un mundo globalizado: 159-202. Barcelona: Ariel.

Ordinas, Antoni. 2001. Geografia i Toponímia a les Illes Balears. La terminologia geogràfica en els noms de lloc. Palma: Ed. Moll.
Ordinas, Antoni y Jaume Binimelis. 2002. «Vindicación de la toponimia como instrumento para el estudio del cambio rural. Rururbanización y neotoponimia en los municipios de Selva e Inca (Mallorca)", en Los espacios rurales entre el hoy y el mañana: Actas del XI Coloquio de Geografía Rural: 285-293. Santander: Universidad de Cantabria.

Ordinas, Antoni y Jaume Binimelis. 2004. "La neotoponímia com a indicador dels canvis a la ruralia de Mallorca. El cas d'Inca i Selva», en Sobre onomàstica. Jornades d'Antroponímia i Toponímia (1993-2002): 349-358. Palma: Universitat de les Illes Balears.

Pastoreau, Michel. 2008. Noir: histoire d'une couleur. París: Editions du Seuil.

Poirier, Jean. 1965. Toponymie. Méthode d'enquête. Quebec: Les Presses de I'Université Laval.

Radding, Lisa y John Western. 2010. "What's in a Name? Linguistics, Geography, and Toponyms». The Geographical Review 100(3): 394-412. doi: <https://doi. org/10.1111/j.1931-0846.2010.00043.x>.

Riesco Chueca, Pascual. 2010. «Nombres en el paisaje: la toponimia, Fuente de conocimiento y aprecio del territorio". Cuadernos Geográficos 46: 7-34.

Roger, Alain (ed.). 2007. Breve tratado del paisaje. Madrid: Editorial Biblioteca Nueva.

Rose-Redwood, Reuben, Derek Alderman y Maoz Azaryahu. 2010. "Geographies of toponymic inscription: new directions in critical place-name studies». Progress in Human Geography 34(4): 453-570. doi: < https://doi.org/10.1177/ 0309132509351042>.

Rosselló Verger, Vicenç M. 2004. Toponímia, geografia i cartografia. València: Universitat de València.

Santamarina, Beatriz. 2013. "Los mapas geopolíticos de la Unesco: entre la distinción y la diferencia están las asimetrías. El éxito (exótico) del patrimonio inmaterial». Revista de antropología social 22: 263-286. doi: <https://doi. org/10.5209/rev_raso.2013.v22.43191>.

Tort, Joan. 2000. «La geografia, els noms de lloc i la descripció del territorio", en Joan F. Mateu y Emili Casanova (eds.), Estudis de Toponímia Valenciana: 491-497. Valencia: Ed. Denes.

Tort, Joan. 2003. «A propòsit de la relació entre toponímia i geografia: el principi de 'significativitat territorial'», en Emili Casanova y Lluis R. Valero (eds.), XXIX Col-loqui de la Societat d'Onomàstica: 675-688. Teulada: Ed. Denes.

Trapero, Maximiano. 1995. "La estructura semántica de los nombres de color en la toponimia. La cromotoponimia de Gran Canaria». Revista de Dialectología y Tradiciones Populares L: 93-124.

Turri, Eugenio. 1979. Semiologia del paesaggio italiano. Milán: Longanesi.

Verne, Jules. 1892. Claudius Bombarnac reporter XXe siècle. Édition du groupe Ebooks libres et gratuits. 